\title{
Increased Levels of Type 1 Interferon in a Type 1 Diabetic Mouse Model Induce the Elimination of B Cells from the Periphery by Apoptosis and Increase their Retention in the Spleen
}

\author{
Badr Mohamed Badra Nadia Ahmed Moustafa ${ }^{b}$ Heba M. Saad Eldien ${ }^{c}$ \\ Amany O. Mohamed ${ }^{d}$ Hany M. Ibrahim ${ }^{a}$ Ibrahim A. El-Elaimy ${ }^{a}$ \\ Mohamed H. Mahmoude,f Gamal Badrg
}

aZoology Department, Faculty of Science, Minufiya University, Shebin El-Kom, Egypt; ${ }^{b}$ Department of Zoology, Faculty of Science, Beni-Suef University, Beni-Suef, Egypt; 'Histology Department, Faculty of Medicine, Assiut University, Assiut, Egypt; dDepartment of Biochemistry, Faculty of Medicine, Assiut

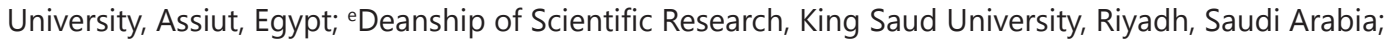
${ }^{f}$ Food Science and Nutrition Department, National Research Center, Dokki, Cairo, Egypt; 'Laboratory of Immunology \& Molecular Biology, Zoology Department, Faculty of Science, Assiut University, Assiut, Egypt

\section{Key Words}

Apoptosis • B-lymphocytes • Diabetes mellitus $\cdot$ IFN- $\alpha \cdot$ Spleen

\begin{abstract}
Background: The autoimmune disease type 1 diabetes mellitus (T1D) is associated with a defect in the immune response, which increases susceptibility to infection. We recently demonstrated that prolonged elevated levels of type 1 interferon (IFN) induce lymphocyte exhaustion during T1D. Aims: In the present study, we further investigated the effect of blocking the type I IFN receptor signaling pathway on diabetic dyslipidemia, in which an abnormal lipid profile leads to the exhaustion of B cells and alteration of their distribution and functions. Methods: T1D was induced in a mouse model by an intraperitoneal injection of a single dose $(60 \mathrm{mg} / \mathrm{kg})$ of streptozotocin (STZ). Three groups of mice were examined: a non-diabetic control group, a diabetic group and a diabetic group treated with an anti-IFN (alpha, beta and omega) receptor 1 (IFNAR1) blocking antibody to block type I IFN signaling. Results: We observed that induction of T1D was accompanied by a marked destruction of $\beta$ cells and a reduction in the insulin levels in the diabetic group. Diabetic mice exhibited many changes, including alterations in their lipid profiles, expansion of splenic B cells, increased caspase- $3,-8$ and -9 activity, and apoptosis in peripheral B cells. Blocking type 1 IFN signaling in diabetic mice significantly returned the insulin and lipid profiles to normal levels, subsequently restored the


B cell distribution, and rescued the peripheral B cells from apoptosis. Conclusion: Our data suggest the potential role of type I IFN in mediating diabetic dyslipidemia and an exhausted state of B cells during T1D.

Copyright $@ 2015$ S. Karger AG, Basel

\section{Introduction}

Type 1 diabetes (T1D) is an autoimmune disease caused by infiltration of lymphoid cells into the pancreatic islets of Langerhans (termed insulitis), followed by the specific destruction of insulin-producing $\beta$ cells [1]. The role of the immune system in the development of T1D, from the initiation of disease to eventual $\beta$ cell destruction, has been studied extensively $[2,3]$. It has been suggested that B cells play a necessary role in diabetes pathogenesis in models of T1D [4-6] by secreting an antibody that is required for diabetes initiation [7] and by presenting self-antigens, including insulin, to autoreactive T cells [8-10]. B cell development proceeds in the spleen of non-obese diabetic (NOD) mice to give rise to two mature subsets: follicular B cells (FoBs) and marginal-zone B cells (MZBs) [11, 12]. MZBs are located within the marginal sinus of the spleen $[12,13]$ and exhibit an activated effector phenotype, as indicated by their ability to generate rapid antibody responses to antigens and blood-borne pathogens [14-17]. In addition, there is emerging evidence from the NOD model that MZBs may be an important B cell subset in diabetes pathogenesis [4] by acting as efficient antigen presenting cells (APCs) to provide antigens to naive CD4+ T cells [18], which play a crucial role in connecting the innate and adaptive immune responses $[12,19]$. In addition, the number of MZBs is significantly increased in NOD mice compared with nonautoimmune-prone strains [20,21].

Multiple complications are usually associated with diabetes mellitus [22]. Patients with type 1 diabetes are subject to lipid disorders, mostly qualitative abnormalities of lipoproteins, which may promote atherogenesis $[23,24]$. Several studies have demonstrated that patients with T1D have significantly higher levels of total cholesterol, triglycerides, lowdensity lipoprotein (LDL) cholesterol and non-high-density lipoprotein (HDL) cholesterol $[25,26]$. Oxidative stress has been implicated in the development of diabetic complications [27] and the pathogenesis of insulin-dependent diabetes mellitus [28-30]. Increased levels of lipid peroxidation products and altered antioxidative enzyme activities have also been reported in non-insulin-dependent diabetes mellitus [31].

Type 1interferons (IFN- $\alpha / \beta$ ) are key immunoregulatory cytokines that provide a priming mechanism for several subsequent processes in the innate and adaptive immune responses [32]. These cytokines are also involved in the pathogenesis of several systemic and organ-specific autoimmune diseases [32]. IFN- $\alpha$ is likely involved in the development of T1D, as evidenced by the overexpression of IFN- $\alpha$ in $\beta$ cell-induced T1D in non-autoimmune-prone C57BL/ 6 mice [33]. In addition, IFN regulatory factor 1-deficient NOD mice fail to develop insulitis and diabetes [34].

However, the specific role of IFN- $\alpha$ in the disruption of B cell proliferation and function during T1D remains unresolved. We recently demonstrated that diabetic mice exhibit increased apoptosis, DNA fragmentation, chromatin condensation and cell shrinkage, prolonged elevation of IFN- $\alpha$ and TNF- $\alpha$ levels, and a clear reduction in Tlymphocytes homing to the spleen [35]. We have also quantified the relationship between type 1IFN signaling and the survival/death and function of peripheral blood mononuclear cells (PBMCs) during T1D [36]. To better understand the role of IFN- $\alpha$ in the etiology of type 1 diabetes, in the present study we examined the number, distribution and function of peripheral B cells and the MZB compartment in streptozotocin (STZ) mice. We provide novel evidence that IFN- $\alpha$ plays a crucial role in MZB expansion and retention in the spleen and the apoptosis of B cells in the blood. 


\section{Materials and Methods}

\section{Chemicals}

STZ was obtained from Sigma Chemicals Co. (St. Louis, MO, USA) and dissolved in cold $0.01 \mathrm{M}$ citrate buffer ( $\mathrm{pH} 4.50$ ) immediately before use (within 5 minutes).

\section{Animals and experimental design}

Laboratory Swiss Webster mice weighing 25-30 g were obtained from the Central Animal House of the Faculty of Medicine, Assiut University. All animal procedures were performed in accordance with the guidelines for the care and use of experimental animals established by the Committee for the Purpose of Control and Supervision of Experiments on Animals (CPCSEA) and the protocol of the National Institute of Health (NIH). The animals were allowed to acclimate for 2 weeks before the experiment and were housed in metal cages in a well-ventilated room. The animals were maintained under standard laboratory conditions $\left(25^{\circ} \mathrm{C}, 60-70 \%\right.$ relative humidity and a 12 -hour light/dark cycle $)$ and were fed a standard commercial pellet diet and water.

Forty Swiss Webster mice were assigned to three experimental groups: group 1, the non-diabetic control group $(n=10)$, was injected with vehicle alone ( $0.01 \mathrm{M}$ citrate buffer, $\mathrm{pH} 4.5$ ); group 2, the diabetic group ( $\mathrm{n}=15$ ), was rendered diabetic by intraperitoneal injection of a single dose of STZ (60 mg per kilogram of body weight) in $0.01 \mathrm{M}$ citrate buffer ( $\mathrm{pH} 4.5)$; group $3(\mathrm{n}=15)$ was rendered diabetic using the same procedure as in group 2 but was also injected intraperitoneally, one month after diabetes induction, with an anti-IFN (alpha, beta and omega) receptor 1 (IFNAR1) antibody at a dose of $10 \mathrm{mg}$ per kilogram of body weight daily for up to 20 days [36, 37].

\section{Blood samples}

At the end of the experiment (after treatment with anti-IFNAR1 for 20 days), the mice were anesthetized with pentobarbital (60 mg per kilogram of body weight), the abdominal cavity was opened, and whole blood was drawn from the abdominal aorta. Plasma was obtained by low-speed centrifugation (1000 $\times$ g for 20 minutes) and immediately stored at $-80^{\circ} \mathrm{C}$ until insulin measurement and lipid profile analysis. PBMCs were isolated from heparinized blood using the Ficoll gradient method.

\section{Insulin level measurement}

Plasma insulin levels were determined by enzyme-linked immunosorbent assay (ELISA) using commercially available kits (R\&D Systems, USA) according to the manufacturer's instructions. The insulin concentration was then calculated using a standard insulin curve included on the same plate as the samples.

\section{Histology and immunohistochemistry}

Spleen and pancreatic tissues were fixed overnight in a solution of freshly prepared $4 \%$ paraformaldehyde in $0.1 \mathrm{M} \mathrm{PBS}, \mathrm{pH} 7.4$, at $4^{\circ} \mathrm{C}$. Samples were dehydrated and prepared as paraffin blocks, and the pancreatic sections were stained with hematoyxlin and eosin (H\&E) and examined by light microscopy. To detect insulin and CD20 in pancreatic and spleen sections, respectively, monoclonal anti-insulin (1:100; DAKO) and anti-CD20 (1:100; Abcam) antibodies were used, respectively. The appropriate primary antibody was added in blocking buffer and incubated overnight at $4{ }^{\circ} \mathrm{C}$. Sections were washed and incubated with biotinylated secondary antibody at 1:2000 for 2 hours at room temperature, followed by washing and incubation with avidin-biotin complex (Vectastain Elite ABC kit; Vector Laboratories, Burlingame, CA, USA) at 1:100 for 1 hour at room temperature. Sections were counterstained with Mayer hematoxylin for 2 to 5 minutes and mounted [38].

\section{Lipid profile analysis}

Lipid profiles were determined using BioMerieux kits and a standard assay method. Cholesterol levels were evaluated using the cholesterol esterase method. Triglycerides were measured using the lipase method. HDL, LDL and chylomicrons were precipitated with phosphotungstic acid. The amount of cholesterol bound to HDL was determined using the cholesterol oxidase method and the phosphotungstate-magnesium salt method using a Cholesterol E-Test Kit (all the kits used were purchased from BioMerieux,Wako, Osaka, Japan) according to the manufacturer's instructions. 


\section{Apoptosis assays}

The percentage of B lymphocytes undergoing apoptosis was determined by flow cytometry. Dead cells were identified using the Trypan blue exclusion test. PBMCs were firstly stained with rat anti-mouse antiCD45R/ B220-PerCP (BD Bioscience) for 30 minutes at $4^{\circ} \mathrm{C}$. To distinguish between viable, early apoptotic and late apoptotic cells, the cells were then washed and incubated in PBS containing 30\% human AB serum $\left(4^{\circ} \mathrm{C}\right.$ for 30 minutes) prior to staining with Annexin V-FITC and propidium iodide (PI) $\left(15\right.$ minutes at $\left.25^{\circ} \mathrm{C}\right)$ using a commercial kit according to the manufacturer's instructions (Abcam, Canada). The cells were analyzed by flow cytometry using a FACSCalibur flow cytometer (BD-Pharmingen) within 1 hour of staining, and the percentage of cells undergoing apoptosis was determined. The activity levels of caspase-3, -8 and -9 were evaluated using a fluorometric protease assay kit (MBL, Aichi, Japan) according to the manufacturer's instructions.

\section{Statistical Analysis}

The data were tested for normality using the Anderson-Darling test and for homogeneity variances prior to further statistical analysis. The data were normally distributed and are expressed as the mean \pm standard error of the mean (SEM). Significant differences among groups were analyzed by one- or two-way ANOVA followed by Bonferroni's test for multiple comparisons using PRISM statistical software (GraphPad Software). The data were also reanalyzed using a one- or two-way ANOVA followed by Tukey's posttest using SPSS software, version 17. Differences were considered statistically significant at $\mathrm{P}<0.05$.

\section{Results}

Treatment of STZ-induced diabetic mice with an anti IFN- $\alpha$ antibody decreases the pathogenicity of $T 1 D$

We recently investigated the effect of STZ-induced immunosuppression in an animal model [36]. First, pancreatic sections from both STZ-treated and naive mice were stained with H\&E and examined by light microscopy. A marked reduction in pancreatic islets was observed in STZ-treated animals compared with naive mice (Fig. 1 A). We then analyzed the architectures of insulin-producing $\beta$ cells within the pancreatic islets of STZ-treated and naive mice by immunohistology. As shown in Fig. 1 B, obvious destruction of insulinproducing $\beta$ cells was observed in the STZ-treated mice compared with naive mice. To optimize the parameters and conditions used in the animal model experiments, the insulin levels in the 3 groups of mice were monitored for 2 months, which revealed that insulin levels in the diabetic group were significantly lower than those in the anti-IFNAR1-treated diabetic group and the control group (Fig. $1 \mathrm{C}$ ). The glucose levels were inversely correlated with the insulin levels where diabetic animals exhibited elevated glucose levels $(394 \pm 27$ $\mathrm{mg} / \mathrm{dl})$ than the anti-IFNAR1-treated diabetic animals (311 $\pm 24 \mathrm{mg} / \mathrm{dl})$ and the control non diabetic animals $(167 \pm 16 \mathrm{mg} / \mathrm{dl})$.

Blockade of type 1IFN signaling restores a normal lipid profile and the number and distribution of $B$ cells in the spleen during T1D in diabetic mice

Atherogenic dyslipidemia clinically presents as elevated serum triglyceride and cholesterol levels, increased levels of low-density lipoprotein (LDL) particles and decreased levels of high-density lipoprotein (HDL). Atherogenic dyslipidemia occurs frequently in patients with diabetes and is referred to as diabetic dyslipidemia. This phenomenon is responsible for inducing immune cell exhaustion. We therefore monitored the lipid profiles of the 3 groups of animals. HDL-C levels were significantly lower in the diabetic mice than in the control non-diabetic group (Fig. 2 A). By contrast, the levels of LDL-C (Fig. 2 B) and cholesterol (Fig. 2 C) were significantly higher in the plasma of diabetic mice compared with the control group. Levels of MDA, a marker of oxidative lipid damage and a major oxidative product of peroxidized polyunsaturated fatty acids, were significantly increased in the plasma of diabetic mice compared with the control non-diabetic group (Fig. 1 D). Interestingly, a normal lipid profile was restored in the diabetic mice when type 1IFN signaling was blockaded with an anti-IFNAR1 antibody. 
Fig. 1. STZ-induced immunosuppressed diabetic mice. (A) Pancreatic sections of both control and STZ-treated mice were stained with $\mathrm{H} \& \mathrm{E}$ and examined by light microscopy (magnification, $\times 40$ ). (B) Pancreatic sections were immunohistochemically stained for islet $\beta$ cells (magnification, $\times 40$ ). (C) Treatment of diabetic mice with an anti-IFNAR1 antibody increased insulin levels during T1D; the levels of insulin were measured in the three groups of mice by ELISA. The results are presented as nanograms of insulin per milliliter of plasma and are expressed as the mean \pm SEM $(n=10) .{ }^{*} \mathrm{P}<$ 0.05 for diabetic versus control; \# $\mathrm{P}<0.05$ for diabetic + anti-IFNAR1 antibody versus diabetic; ${ }^{+} \mathrm{P}<0.05$ for diabetic + anti-IFNAR1 versus control.

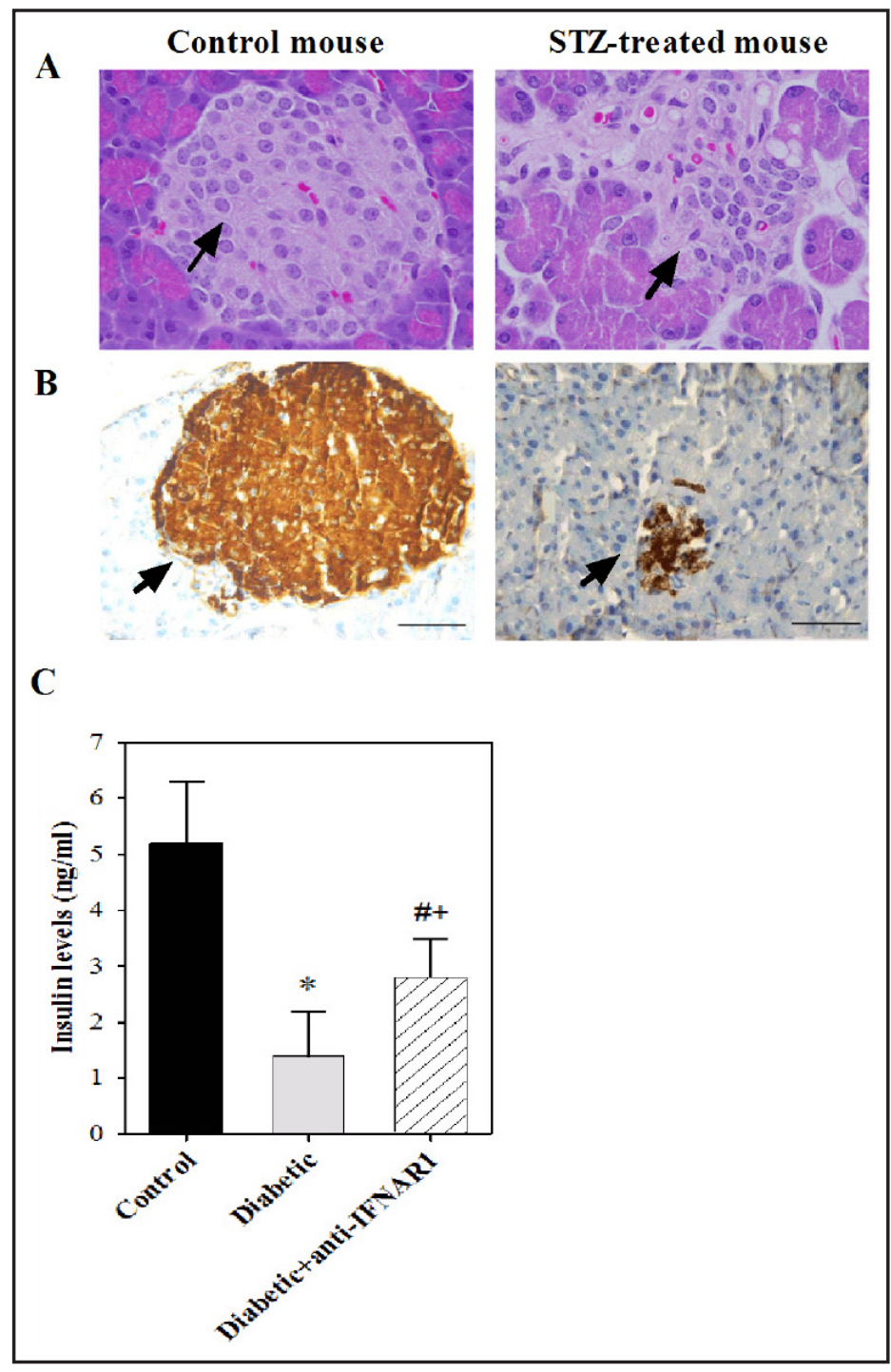

Blockade of type 1IFN signaling decreases $B$ cell infiltration and retention in the spleen during T1D

An imbalance in splenic B cell development resulting in expansion of the MZ subset has been associated with autoimmune pathogenesis in various murine models [39], including the NOD inbred mouse strain, in which splenic marginal zone (MZ) B cell expansion has been linked to the development of T1D [40]. Therefore, the numbers of CD20-positive B cells in the spleens of control, diabetic and anti-IFNAR1-treated mice were estimated. Compared with control non-diabetic mice (Fig. $3 \mathrm{~A}$ ), the numbers of B cells in the spleens of diabetic mice were obviously higher in the periarterial lymphatic sheath, with moderate numbers in the germinal center and follicle of the lymphatic nodules (Fig. 3 B). Interestingly, splenic B cell levels were restored in the anti-IFNAR1-treated diabetic mice (Fig. 3 C).

Injection of anit-IFNRA1 during type 1diabetes increase apoptosis of blood B cells

We next evaluated the number of B cells circulating in the blood and their tendency to undergo apoptosis in the three groups of animals. B cells isolated from control, diabetic and anti-IFNAR1-treated diabetic mice were stained with PI/Annexin V and analyzed by flow cytometry to determine the percentages of viable cells (lower left quadrant), early apoptotic cells (lower right quadrant) and late apoptotic cells (upper right quadrant) (Fig. 4 A). The data from one representative experiment are presented in the dot plot. The percentage 
Fig. 2. Blocking the type 1IFN receptor restores the lipid profile in diabetic mice. The levels of HDL-C (A), LDL-C (B), cholesterol (C) and MDA (D) were determined in control mice (black bars), diabetic mice (gray bars) and diabetic mice treated with an anti-IFNAR1 blocking antibody (hatched bars) as described in the Materials and Methods. The pooled data for 10 individual mice from each group are expressed as the mean level of each lipid \pm SEM. ${ }^{*}$ P $<0.05$ for diabetic versus control; ${ }^{\#} \mathrm{P}<0.05$ for diabetic + anti-IFNAR1 antibody versus diabetic; ${ }^{+} \mathrm{P}<$ 0.05 for diabetic + antiIFNAR1 versus control.
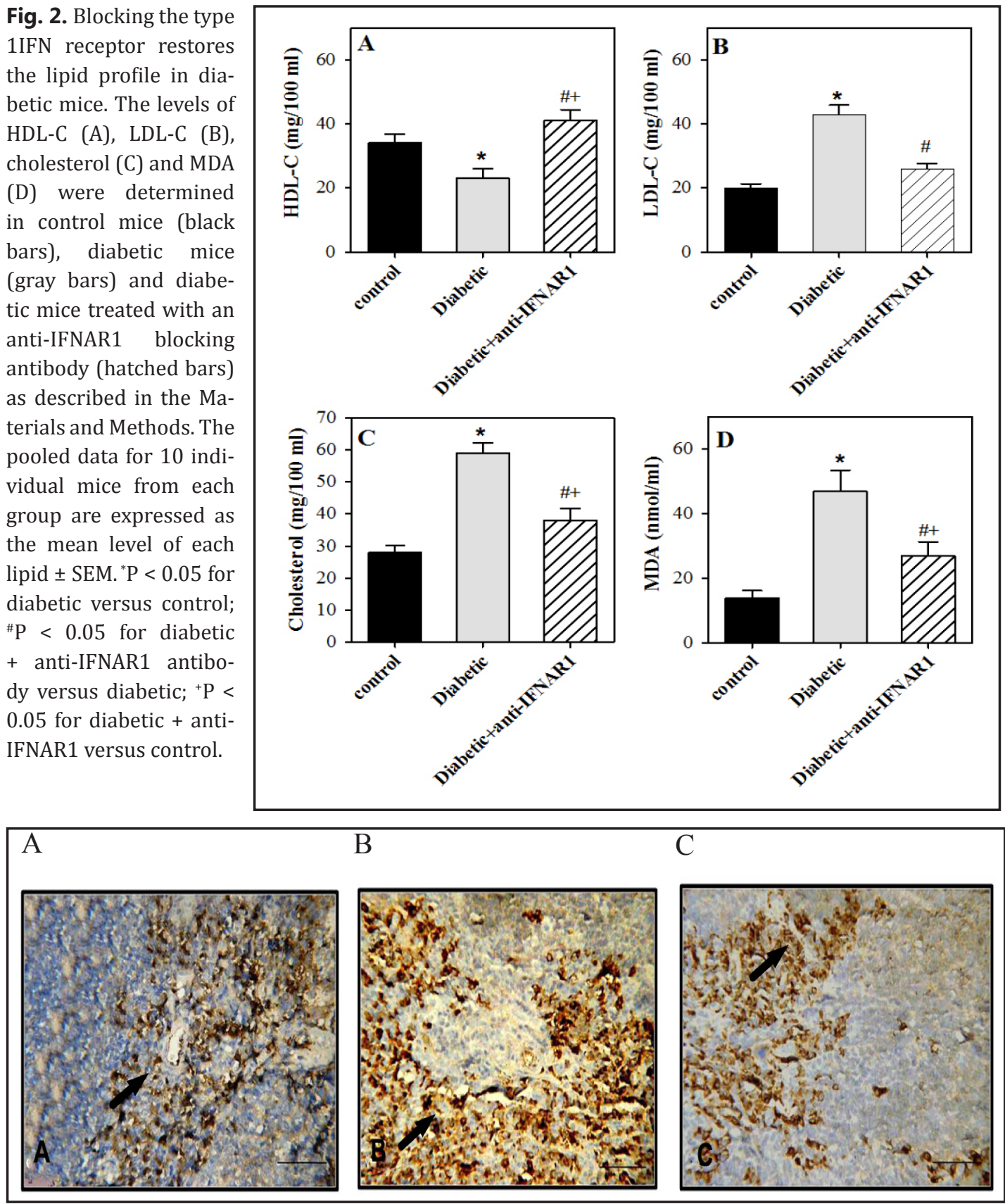

Fig. 3. IFN- $\alpha$ increases the retention of B cells in the spleen during T1D. CD20 $0^{+} \mathrm{B}$ cells in mouse spleens were detected by immunohistochemical analysis (Immunoperoxidase X40). (A) In the spleens of control animals, low numbers of B cells in the periarterial lymphatic sheath and moderate numbers of B cells in the germinal center and follicle of the lymphatic nodules were observed. (B) In the spleens of diabetic animals, an increase in the numbers of B cells in the germinal center of the lymphatic nodules was observed compared with control mice. (C) A decreased number of B cells in the germinal center of the lymphatic nodules was observed in the spleens of diabetic mice treated with an anti-IFNAR1 antibody compared with diabetic mice.

of apoptotic B cells (early and late apoptotic) was $9 \%$ in the control non-diabetic group and increased markedly to $61 \%$ in the diabetic group; the percentage of apoptotic B cells decreased to $38 \%$ when the diabetic animals were treated with an anti-IFNAR1 antibody. 
Fig. 4. Blocking the type 1IFN receptor decreases caspase activity and apoptosis in B lymphocytes in diabetic mice. Viable, apoptotic and necrotic $\mathrm{B}$ lymphocytes (CD45R/ B220+ cells) were differentiated by flow cytometry based on their PI/Annexin $\mathrm{V}$ staining patterns. (A) A dot plot of one representative data set from 10 independent experiments is shown. (B) Pooled data from 10 experiments are expressed as the mean percentage of apoptotic B cells \pm SEM for

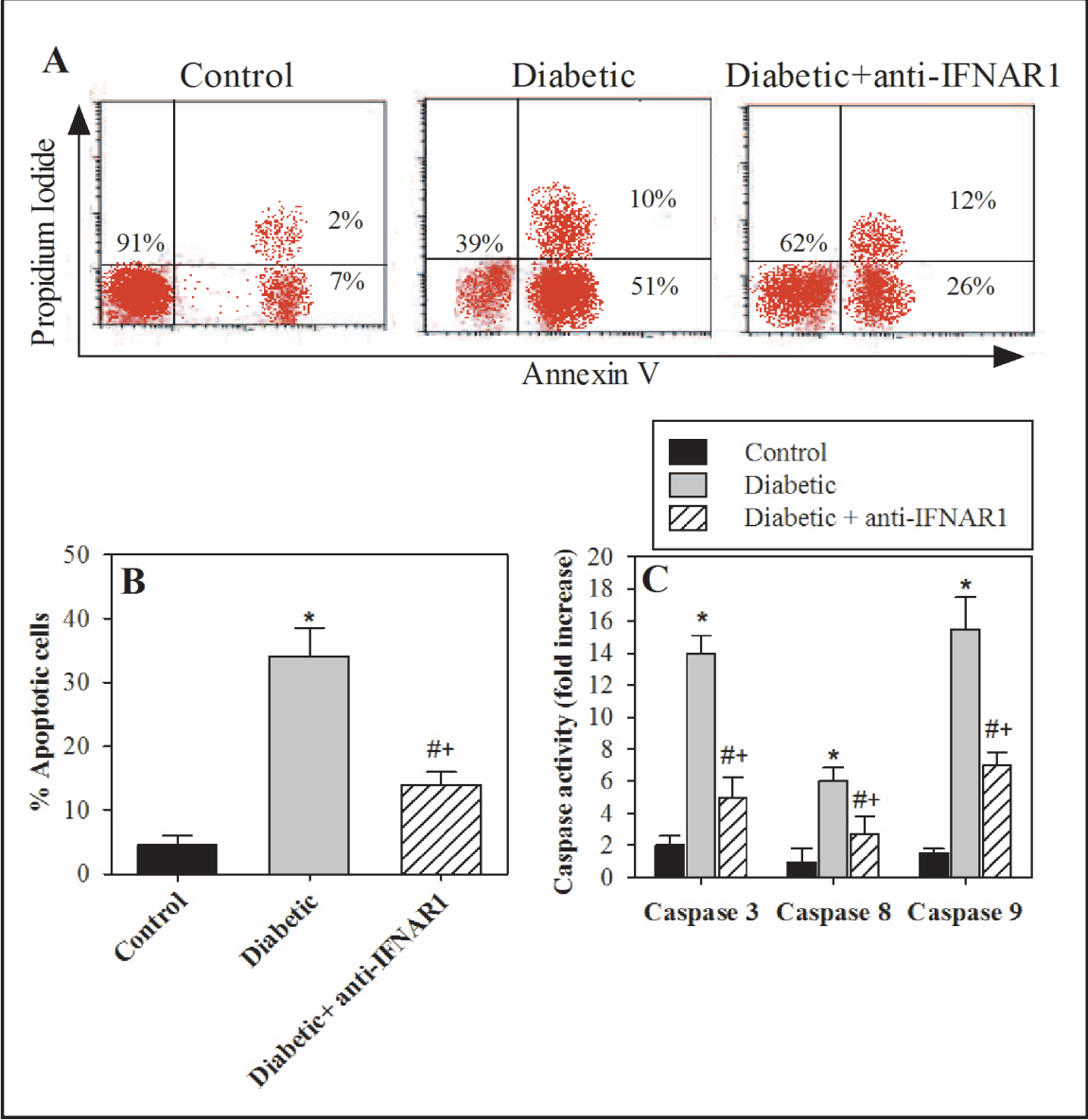

B lymphocytes isolated from control mice (black bars), diabetic mice (gray bars) and diabetic mice treated with an anti-IFNAR1 blocking antibody (hatched bars). B lymphocytes were isolated from control, diabetic and diabetic+anti-IFNAR1 mice and lysed, and the caspase-3, -8 and -9 activity levels were evaluated using a fluorometric protease assay. The data for 10 individual mice from each group are expressed as the mean \pm SEM. ${ }^{*} \mathrm{P}<0.05$ for diabetic versus control; ${ }^{~} \mathrm{P}<0.05$ for diabetic + anti-IFNAR1 versus diabetic; ${ }^{+} \mathrm{P}<0.05$ for diabetic + anti-IFNAR1 antibody versus control.

The pooled data for 10 individual mice from each group indicated that treatment of the diabetic mice with an anti-IFNAR1 antibody significantly $(\mathrm{P}<0.05)$ rescued $\mathrm{B}$ cells from apoptosis (Fig. 4 B). Because caspase cascades are crucial effectors and mediators of apoptosis induction, the activities of caspase-3, -8 and -9 in blood B cells (Fig. 4 C) were monitored using a fluorometric protease assay. The pooled data for 10 individual mice from each group revealed that the activities of caspase- $3,-8$ and -9 in blood B cells of diabetic mice were significantly greater than those in the control non-diabetic mice. Moreover, treatment of the diabetic mice with an anti-IFNAR1 antibody significantly diminished the activities of caspase-3, -8 and -9 in blood B cells compared with the diabetic mice that did not receive the antibody.

\section{Discussion}

Type 1 diabetes is characterized by a decrease in the number of lymphocytes, which increases susceptibility to infection. Considerable data support a link between IFN- $\alpha$ and T1D in humans and in rodent models, with increased levels of IFN- $\alpha$ in the serum and increased mRNA expression in the pancreases of T1D patients [41]. Moreover, IFN- $\alpha$ may 
contribute to the initiation or acceleration of autoimmunity [42], and IFN- $\alpha$ is expressed in the islets of patients with newly diagnosed type 1 diabetes [43]. Furthermore, as with certain other autoimmune diseases, T1D occasionally appears during IFN- $\alpha$ treatment of unrelated diseases such as chronic hepatitis or tumors $[44,45]$. Moreover, diabetes is also induced and/or accelerated by injections of the strong IFN- $\alpha / \beta$ inducer poly I:C in the STZ-induced diabetic mouse model [46]. We previously demonstrated that blocking type 1IFN signaling restored the number of T lymphocytes homing to lymphoid organs in Swiss albino mice [35]. We have further extended this work by revealing that blocking type 1IFN signaling in an STZ diabetic mouse model restores lymphocyte function [36].

Interestingly, in the present study, the induction of diabetes was associated with decreased levels of insulin and quantitative lipid abnormalities, indicating that insulin deficiency plays a crucial role in lipid abnormalities during T1D. These results are consistent with previous results revealing that insulin plays a central role in the regulation of lipid metabolism [47]. Insulin deficiency, hypertriglyceridemia and reduced HDL commonly occur during T1D and are thought to play a physiological role in lipid/lipoprotein metabolism [48]. Indeed, the results presented here demonstrate that blocking type 1IFN signaling during diabetes partially yet significantly decreased lipid abnormalities in T1D. These findings are consistent with studies suggesting that lipid abnormalities in immunodeficiency diseases are mediated by elevated levels of circulating inflammatory cytokines, particularly interferon- $\alpha$ $[49,50]$. Thus, lipid abnormalities during T1D produce several abnormal biological responses that play a key role in the development of defective immune responses during diabetes, leading to different diseases [51]. Hyperglycemia acts as a potential mediator of altered lymphocyte function, which can lead to enhanced oxidative stress, and plays a key role in the development of defective immune responses during diabetes [42, 52]. MDA is also thought to play a physiological role in oxidative stress and may cause damage to cellular components $[43,53]$.

In the present study, the contribution of different B cell subsets was determined based on their relative ratios at specific anatomical locations and their activation status. A significant increase in MZBs was observed in STZ diabetic mice. However, blocking type 1IFN signaling restored the number of MZBs. Consistent with our results, expansion of MZBs by 2- to 3-fold in NOD mice compared with nondiabetic C57BL/6 (B6) mice has been reported, reflecting an elevated number of autoreactive B cells in the autoimmune NOD mouse [20]. An imbalance in splenic B cell development resulting in the expansion of the MZ subset has been associated with autoimmune pathogenesis in various murine models [39]. For example, in the NOD inbred mouse strain, splenic MZB cell expansion has been linked to the development of T1D [40]. MZB cells are suggested to be enriched in autoreactive specificities, and an enlargement of the MZB compartment has been implicated in T1D $[20,39]$. In this regard, the PLN is recognized as a critical site for the presentation of autoantigen to self-reactive T-cells [54-56]. The increased accumulation of MZB-like cells at this site has been closely linked to the conversion to overt diabetes in the NOD model [39].

We observed a significant increase in expression of caspase-3, - 8 and -9 and a decrease in the number of CD20+ B lymphocytes in the peripheral blood of STZ diabetic mice, leading us to hypothesize that the retention of activated MZBs in the spleen leads to the elimination of other subsets of $B$ cells. Taken together, our data suggest that IFN- $\alpha$ mediates the retention of B lymphocytes within lymphoid organs during type 1diabetes, resulting in a local increase in lymphocyte numbers in the responding lymphoid organ but systemic immunosuppression as a result of the depletion of recirculating B lymphocytes.

\section{Abbreviations}

Anti-interferon (alpha/beta/omega) receptor 1(IFNAR1); High-density lipoprotein (HDL); Low-density lipoprotein (LDL); Peripheral blood mononuclear cells (PBMCs); Type 1diabetes mellitus (T1D); Type 1 interferon (IFN); Streptozotocin (STZ). 
Badr et al.: Type 1 IFN as an Exhaustion Marker for B Lymphocytes in Type 1 Diabetes

\section{Disclosure Statement}

The authors declare no conflicts of interest. This manuscript has not been published or submitted elsewhere. This work complies with the Ethical Policies of the Journal and has been conducted under internationally accepted ethical standards after relevant ethical review.

\section{Acknowledgments}

The authors would like to extend their sincere appreciation to the Deanship of Scientific Research at king Saud University for its funding this Research group NO (RG -1435-019).

\section{References}

1 Kelemen K: The role of T cells in beta cell damage in NOD mice and humans. Adv Exp Med Biol 2004;552:117-128.

2 Thomas H, Kay T: Beta cell destruction in the development of autoimmune diabetes in the non-obese diabetic (NOD) mouse. Diabetes Metab Res Rev 2000;16:251-261.

3 Beyan H, Buckley L, Yousaf N, Londei M, Leslie R: A role for innate immunity in type 1 diabetes. Diabetes Metab Res Rev 2003;19:89-100.

4 Silveira PA, and Grey ST: B-cells in the spotlight: innocent bystanders or major players in the pathogenesis of type 1 diabetes. Trends Endocrinol Metab 2006;17:128-135.

-5 Noorchashm H, Noorchashm N, Kern J, Rostami SY, Barker CF, Naji A: B-cells are required for the initiation of insulitis and sialitis in nonobese diabetic mice. Diabetes 1997;46:941-946.

-6 Serreze DV, Chapman HD, Varnum DS, Hanson MS, Reifsnyder PC, Richard SD, Fleming SA, Leiter EH, Shultz LD: B lymphocytes are essential for the initiation of T cell-mediated autoimmune diabetes: analysis of a new "speed congenic" stock of NOD.Ig mu null mice. J Exp Med 1996;184:2049-2053.

7 Greeley SA, Katsumata M, Yu L, Eisenbarth GS, Moore DJ, Goodarzi H, Barker CF, Naji A, Noorchashm H: Elimination of maternally transmitted autoantibodies prevents diabetes in nonobese diabetic mice. Nat Med 2002;8:399-402.

8 Noorchashm H, Lieu YK, Noorchashm N, Rostami SY, Greeley SA, Schlachterman A, Song HK, Noto LE, Jevnikar AM, Barker CF, Naji A: I-Ag7-mediated antigen presentation by B lymphocytes is critical in overcoming a checkpoint in $\mathrm{T}$ cell tolerance to islet beta cells of nonobese diabetic mice. J Immunol 1999;163:743-750.

-9 Serreze DV, Fleming SA, Chapman HD, Richard SD, Leiter EH, Tisch RM: B lymphocytes are critical antigenpresenting cells for the initiation of T cell-mediated autoimmune diabetes in nonobese diabetic mice. J Immunol, 1998;161:3912-3918.

10 Falcone M, Lee J, Patstone G, Yeung B, Sarvetnick N: B lymphocytes are crucial antigen-presenting cells in the pathogenic autoimmune response to GAD65 antigen in nonobese diabetic mice. J Immunol 1998;161:1163-1168.

11 Loder F, Mutschler B, Ray RJ, Paige CJ, Sideras P, Torres R, Lamers MC, Carsetti R: B-cell development in the spleen takes place in discrete steps and is determined by the quality of B-cell receptor-derived signals. J Exp Med 1999;190:75-89.

12 Martin F and Kearney JF: B-cell subsets and the mature preimmune repertoire. Marginal zone and B1 B-cells as part of a "natural immune memory. Immunol Rev 2000;175:70-79.

13 Pillai S, Cariappa A, Moran ST: Marginal zone B-cells. Annu Rev Immunol 2005;23:161-196.

14 Song H and Cerny J: Functional heterogeneity of marginal zone B-cells revealed by their ability to generate both early antibody-forming cells and germinal centers with hypermutation and memory in response to a T-dependent antigen. J Exp Med 2003;198:1923-1935.

15 Snapper CM, Yamada H, Smoot D, Sneed R, Lees A, Mond JJ: Comparative in vitro analysis of proliferation, Ig secretion, and Ig class switching by murine marginal zone and follicular B-cells. J Immunol 1993;150:2737-2745. 
16 Oliver AM, Martin F, Kearney JF: IgMhighCD21high lymphocytes enriched in the splenic marginal zone generate effector cells more rapidly than the bulk of follicular B-cells. J Immunol 1999;162:7198-7207.

17 Oliver AM, Martin F, Gartland GL, Carter RH, Kearney JF: Marginal zone B-cells exhibit unique activation, proliferative and immunoglobulin secretory responses. Eur J Immunol 1997;27:2366-2374.

18 Attanavanich K and Kearney JF: Marginal zone, but not follicular B-cells, are potent activators of naive CD4 T cells. J Immunol 2004;172:803-811.

19 Martin F, Oliver AM, Kearney JF: Marginal zone and B1 B-cells unite in the early response against T-independent blood-borne particulate antigens. Immunity 2001;14:617-629.

-20 Rolf J, Motta V, Duarte N, Lundholm M, Berntman E, Bergman ML, Sorokin L, Cardell SL, Holmberg D: The enlarged population of marginal zone/ CD1d(high) B lymphocytes in nonobese diabetic mice maps to diabetes susceptibility region Idd11. J Immunol 2005;174:4821-4827.

-21 Quinn WJ, Noorchashm N, Crowley JE, Reed AJ, Noorchashm H, Naji A, Cancro MP: Cutting edge: impaired transitional B-cell production and selection in the nonobese diabetic mouse. J Immunol 2006;176:71597164.

22 Thompson CS: Animal models of diabetes mellitus: relevance to vascular complications. Curr Pharm Des 2008;14:309-324.

23 Soedamah-Muthu SS, Chaturvedi N, Toeller M, Ferriss B, Reboldi P, Michel G, Manes C, Fuller JH: Risk factors for coronary heart disease in type 1 diabetic patients in Europe the EURODIAB Prospective Complications Study. Diabetes Care 2004;27:530-537.

24 Grauslund J, Jørgensen TM, Nybo M, Green A, Rasmussen LM, Sjølie AK: Risk factors for mortality and ischemic heart disease in patients with long-term type 1 diabetes. J Diabetes Complications 2010;24:223228.

25 Edge JA, James T, Shine B: Longitudinal screening of serum lipids in children and adolescents with Type 1 diabetes in a UK clinic population. Diabet Med 2008;25:942-948.

26 Maahs DM, Ogden LG, Dabelea D, Snell-Bergeon JK, Daniels SR, Hamman RF, Rewers M: Association of glycaemia with lipids in adults with type 1 diabetes: modification by dyslipidaemia medication. Diabetologia 2010;53:2518-2525.

27 Theofilopoulos AN, Baccala R, Beutler B, Kono DH: Type 1interferons (alpha/beta) in immunity and autoimmunity. Annu Rev Immunol 2005;23:307-336.

28 Baynes JW: Role of oxidative stress in development of complications in diabetes. Diabetes 1991;40:405412.

29 Jain SK: Hyperglycemia can cause membrane lipid peroxidation and osmotic fragility in human red blood cells. J Biol Chem 1989;264:21340-21345.

30 Orhan H and Sahin G: Erythrocyte glutathione S-transferase activity in diabetes mellitus: the effect of the treatment. ABAD J Pharm Sci 1999;24:127-131.

- 31 Sato Y, Hotta N, and Sakamoto N: Lipid peroxide level in plasma of diabetic patients. Biochem Med 1979;21:104-107.

- 32 Kaji H, Kurasaki M, and Ito K: Increased lipoperoxide value and glutathione peroxidase activity in blood plasma of type 2 (non-insulin-dependent) diabetic women. Klin Wochenschr 1985;63:765-768.

-33 Stewart TA, Hultgren B, Huang X, Pitts-Meek S, Hully J, MacLachlan NJ: Induction of type 1diabetes by interferon-alpha in transgenic mice. Science 1993;260:1942-1946.

-34 Nakazawa T, Satoh J, Takahashi K, Sakata Y, Ikehata F, Takizawa Y, Bando SI, Housai T, Li Y, Chen C, Masuda T, Kure S, Kato I, Takasawa S, Taniguchi T, Okamoto H, Toyota T: Complete suppression of insulitis and diabetes in NOD mice lacking interferon regulatory factor-1. J Autoimmunity 2011;17:119-125.

35 Saad Eldien HM, El-Elaimy IA, Ibrahim HM, Badr BM, Badr G: Increased level of Type 1Interferon during Type 1diabetes induces apoptosis in spleen-homing T cells. African J Pharm Pharmacol 2012;6:2675-2681.

-36 Ibrahim HM, El-Elaimy IA, Saad Eldien HM, Badr BM, Rabah DM, Badr G: Blocking type 1interferon signaling rescues lymphocytes from oxidative stress, exhaustion, and apoptosis in a streptozotocin-induced mouse model of type 1diabetes. Oxid Med Cell Longev 2013;12:148725.

- 37 Badr G, Waly H, Saad Eldien HM, Abdel-Tawab H, Hassan K, Alhazza IM, Ebaid H, Alwasel SH: Blocking type 1interferon (IFN) signaling impairs antigen responsiveness of circulating lymphocytes and alters their homing to lymphoid organs: protective role of type 1IFN. Cell Physiol Biochem 2010;26:1029-1040. 


\section{Cellular Physiology $\quad$ Cell Physiol Biochem 2015;35:137-147 and Biochemistry

- 38 Kashino SS, Vallerskog T, Martens G, Troudt J, Keyser A, Taylor J, Izzo A, Kornfeld H, Campos-Neto A: Initiation of Acquired Immunity in the Lungs of Mice Lacking Lymph Nodes after Infection with Aerosolized Mycobacterium tuberculosis. Am J Pathol 2010;176:198-204.

-39 Marino E, Batten M, Groom J, Walters S, Liuwantara D, Mackay F, Grey ST: Marginal zone B cells of Nonobese diabetic mice expand with diabetes onset; invade the pancreatic lymph nodes and present autoantigen to diabetogenic T cells. Diabetes 2008;57:395-404.

-40 Stolp J, Mariño E, Batten M, Sierro F, Cox SL, Grey ST, Silveira PA: Intrinsic molecular factors cause aberrant expansion of the splenic marginal zone B cell population in nonobese diabetic mice. J Immunol 2014;191:97-109.

-41 Huang X, Yuang J, Goddard A, Foulis A, James RF, Lernmark A, Pujol-Borrell R, Rabinovitch A, Somoza $\mathrm{N}$, Stewart TA: Interferon expression in the pancreases of patients with type 1diabetes. Diabetes 1995;44:658-664.

42 Baynes JW: Role of oxidative stress in the development of complications in diabetes. Diabetes 1991; 40:405-412.

43 Rosen P, Nawroth PP, King G, Moller W, Tritschler HJ, Packer L: The role of oxidative stress in the onset and progression of diabetes and its complications: a summary of a Congress Series sponsored by UNESCOMCBN, the American Diabetes Association and the German Diabetes Society. Diabetes Metab Res Rev 2001;17:189-212.

44 Fabris P, Floreani A, Tositti G, Vergani D, De Lalla F, Betterle C: Type 1 diabetes mellitus in patients with chronic hepatitis C before and after interferon therapy. Aliment Pharmacol Ther 2003;18:549-558.

45 Guerci AP, Guerci B, Lévy-Marchal C, Ongagna J, Ziegler O, Candiloros H, Guerci O, Drouin P: Onset of insulin-dependent diabetes mellitus after interferon- $\alpha$ therapy for hairy cell leukaemia. Lancet 1994;343:1167-1168.

46 Huang X, Hultgren B, Dybdal N, Stewart TA: Islet expression of interferon- $\alpha$ precedes diabetes in both the BB rat and streptozotocin-treated mice. Immunity 1994;1:469-478.

-47 Vergès B: Insulin sensitiviy and lipids. Diabetes Metab 2001;27:223-227.

48 Ginsberg HN: Diabetic dyslipidemia: basic mechanisms underlying the common hypertriglyceridemia and low HDL cholesterol levels. Diabetes 1996;45:27-30.

-49 Hellerstein MK, Grunfeld C, Wu K, Christiansen M, Kaempfer S, Kletke C, Shackleton CH: Increased de novo hepatic lipogenesis in human immunodeficiency virus infection. J Clin Endocrinol Metab 1993;76:559-565.

50 Tominaga M, Uno K, Yagi K, Fukui M, Hasegawa G, Yoshikawa T, Nakamura N: Association between capacity of interferon-alpha production and metabolic parameters. J Interferon Cytokine Res 2010;30:451-454.

51 Chan AC: Vitamin E and atherosclerosis. J Nutr 1998;128:1593-1596.

52 Whitacre CM and Cathcart MK: Oxygen free radical generation and regulation of proliferative activity of human mononuclear cells responding to different mitogens. Cell Immunol 1992;144: 287-295.

-53 Burdon RH: Superoxide and hydrogen peroxide in relation to mammalian cell proliferation. Free Radic Biol Med 1995;18:775-794.

-54 Jaakkola I, Jalkanen S, Hanninen A: Diabetogenic T cells are primed both in pancreatic and gut-associated lymph nodes in NOD mice. Eur J Immunol 2003;33:3255-3264.

-55 Hoglund P, Mintern J, Waltzinger C, Heath W, Benoist C, Mathis D: Initiation of autoimmune diabetes by developmentally regulated presentation of islet cell antigens in the pancreatic lymph nodes. J Exp Med 1999;189:331-339.

56 Gagnerault MC, Luan JJ, Lotton C, Lepault F: Pancreatic lymph nodes are required for priming of beta cell reactive T cells in NOD mice. J Exp Med 2002;196:369-377. 